\title{
Is the risk of cancer increased in Asians living in the UK?
}

\author{
J E Powell, S E Parkes, A H Cameron, J R Mann
}

\begin{abstract}
The pattern of cancer in white and Asian (Indian, Pakistani, and Bangladeshi) children living in the West Midlands Health Authority Region was investigated using age standardised incidence rates. Two sets of rates were calculated, a 10 year rate (1982-91) using survey based estimates of the ethnic population and a four year rate (1989-92) using the ethnic population counts from the 1991 census. The 10 year rates showed a significantly higher annual incidence of cancer in Asian (159.1/million/year) than in white $(130 \cdot 8)$ children. The pattern of cancers in Asian children was different, with an excess of lymphomas and germ cell tumours, and a deficit of rhabdomyosarcomas. These findings were confirmed by the four year rates. Although underestimation of the Asian population probably contributes to the apparent excess, there remains cause for concern that UK Asian children may be at higher risk of cancer. Accurate ethnic population figures and confirmatory studies are urgently required.
\end{abstract}

(Arch Dis Child 1994; 71: 398-403)

Studies of the incidence of cancer in ethnic groups can provide valuable insight into its causes. The study of immigrant populations can be especially rewarding, as changes towards the pattern of disease seen in the host country may indicate environmental factors in the aetiology. Incidence rates for childhood cancer are available from registries throughout the world ${ }^{1}$ and in the USA ethnic variations in the patterns of childhood cancer are well documented. ${ }^{2-5}$

In the UK there has been little research into ethnic variations in childhood cancers, though ethnic minorities comprise up to $27 \%$ of the population in some metropolitan boroughs. ${ }^{6} \mathrm{~A}$ study $^{7}$ of the UK Children's Cancer Study Group (UKCCSG) database (consisting of children treated at UK paediatric oncology centres between 1981 and 1988) suggested that there may be an increased risk of Hodgkin's disease and a reduced risk of Wilms' tumour and rhabdomyosarcoma in Asian children living in the UK. An earlier study of Asians in the West Midlands ${ }^{8}$ detected a significant excess of solid tumours and noted that Hodgkin's disease, retinoblastoma, and neuroblastoma were proportionately more common. In both of these studies, the relative frequencies of tumour types were compared in different populations.

Age standardised incidence rates are the most informative statistics for analysing the pattern of cancer occurrence in different populations. Until now, however, figures have not been produced for ethnic minorities in the UK. This is because population based cancer registries rarely record the ethnic origin of the patient and age standardised incidence rates must be based on reliable population figures.

This paper presents, for the first time, incidence rates for cancer in white (European) and Asian (Indian, Pakistani, and Bangladeshi) children living in the UK. The target population resides in the West Midlands Health Authority Region (WMHAR). This region contains almost $10 \%$ of the UK population, including one million children under 15 years. The ethnic minorities comprise $7 \cdot 3 \%$ of its total population and nearly $14 \%$ of the children. The Asians are the largest minority group $(66 \%)$ and are thought to account for $9 \%$ of all children in the region. ${ }^{6}$

\section{Methods}

Age standardised incidence rates were derived for cases of cancer in children aged under 15 years resident in the WMHAR between 1982 and 1992. Cases were detected from the records of the West Midlands Regional Children's Tumour Research Group (WMRCTRG). ${ }^{8}$ The WMRCTRG maintains a population based register of all cases of childhood cancer diagnosed in residents of the WMHAR. The clinical records of all cases were reviewed and histopathological review was undertaken in the $89 \%$ of cases where material was available. Ethnic origin was determined from the medical notes of the patient or, where not stated, from the general practitioner or consultant responsible for care.

Calculation of age standardised incidence rates for ethnic minorities in the UK is complicated by the fact that, until recently, the size of the UK ethnic population was imprecisely known. Population figures for the UK are derived from the decennial census, carried out

Regional Children's
Tumour Research
Group, The Children's
Hospital, Ladywood
Middleway, Ladywood,
Birmingham B16 8ET
J E Powell
S E Parkes
A H Cameron
J R Mann
Correspondence to:
Dr Powell.

Accepted 30 June 1994 
Table 1 Childhood population of the WMHAR

\begin{tabular}{lccc}
\hline Source & White & Asian & All ethnic groups \\
\hline Labour Force Survey (1986-8) & & & \\
Estimate (thousands) & 853.62 & 92.95 & $1017 \cdot 26$ \\
$\begin{array}{l}\text { 95\% Confidence intervals } \\
\text { \% Of total }\end{array}$ & $828 \cdot 8$ to 878.4 & 73.5 to 112.4 & - \\
Census (1991) & 83.9 & $9 \cdot 1$ & 100 \\
Count (thousands) & 848.32 & $96 \cdot 10$ & $991 \cdot 22$ \\
\% Of total & 85.6 & $9 \cdot 7$ & 100 \\
\hline
\end{tabular}

by the Office of Population Censuses and Surveys (OPCS). Ethnic breakdowns of the population have only recently become available with the publication of results from the 1991 census, which specifically asked a question about ethnic origin. Before 1991, only estimates of the ethnic population were available, derived from the OPCS Labour Force Survey. This is an annual survey of 60000 private households in the $\mathrm{UK}$, containing about 150000 people, including about 7000 members of the ethnic minorities. ${ }^{6}$

Age standardised incidence rates were first calculated for the 10 year period 1982-91. Approximately $120-140$ new cases of childhood cancer arise each year in the WMHAR and a 10 year period was required to smooth out random fluctuations and to accrue sufficient Asian patients for different types of cancer to be studied. Figures for the childhood population at risk during this period were calculated using the grossed up estimates for 1987, derived from three Labour Force Surveys carried out between 1986 and 1988 and provided by OPCS. By combining the results of three consecutive surveys, the effects of random sampling error were reduced. Confidence intervals (95\%) for these population estimates were derived based on a sampling fraction of one in 350 and a survey design factor of $1 \cdot 8 .^{6}$

For comparison, rates were then calculated for the four year period 1989 to 1992 . In this instance the age standardised incidence rates were based on actual population figures derived from the 1991 census, rather than estimates. The small number of cases accrued in the four year period may have affected their reliability, however (age standardised incidence rates based on fewer than 10 cases are thought to be unreliable ${ }^{1}$ ). For both Labour Force Survey and census derived populations, the category 'Asian' consisted of those people described as either Indian, Pakistani, or Bangladeshi.

Age standardised incidence rates were calculated for several diagnostic categories of tumour, based on the Birch-Marsden classification system. ${ }^{9}$ The rates for Asian and white children were compared using the standardised rate ratio. ${ }^{10}$ Where the $95 \%$ confidence interval did not include the value 1.00 the difference was regarded as statistically significant.

The accuracy of the population figures was checked by comparing them with records of the ethnic origin of schoolchildren in Birmingham. Finally, we examined the effect on the age standardised incidence rates of underestimating the population size.

\section{Results}

In the 11 year period between 1982 and 1992, the WMRCTRG registered 1420 cases of malignant disease in children under 15 years of age. Of these, 1188 were in white children, 161 in Asian children, 28 in Afro-Caribbeans, and 43 in children of other or mixed race.

Table 1 gives the estimated population figures for 1987 (with 95\% confidence intervals) and the 1991 census counts for white and Asian children. Table 2 shows the age standardised incidence rates for Asian and white children based on the 10 year period 1982-91. Also shown are the number of cases recorded for each diagnostic category and the standardised rate ratio (for Asians compared with whites) and $95 \%$ confidence intervals. Note that with multiple tests of significance, one significant $(p<0.05)$ value in each table would be expected by chance alone.

The incidence of all malignancies was significantly higher in the Asians (standardised rate ratio $1 \cdot 22$ ), notably for lymphomas, for which the rate was twice that found in white children. Solid tumours were also significantly more common (standardised rate ratio 1.4 ) in Asians, the excess consisting of non-sarcomatous solid tumours. A significant excess of

Table 2 Age standardised incidence rates (ASRs) and standardised rate ratio (SRR) for childhood cancer in the WMHAR, $1982-91$ (10 year period) (population figures derived from 1986-8 Labour Force Surveys)

\begin{tabular}{|c|c|c|c|c|c|}
\hline \multirow[b]{2}{*}{ Tumour type } & \multicolumn{2}{|l|}{ White } & \multicolumn{2}{|l|}{ Asian } & \multirow[b]{2}{*}{$S R R(95 \% C I)$} \\
\hline & No of cases & $A S R^{\star}(95 \% C I)$ & No of cases & $A S R^{\star}(95 \% C I)$ & \\
\hline Lymphoreticular tumours & 438 & $52 \cdot 8(47.9$ to $57 \cdot 8)$ & 64 & $69 \cdot 9(52 \cdot 7$ to $87 \cdot 1)$ & $1.32(0.99$ to 1.77$)$ \\
\hline Leukaemias & 344 & $42.4(37.9$ to 46.9$)$ & 44 & $48.9(34.4$ to 63.4$)$ & $1.15(0.83$ to 1.61$)$ \\
\hline Acute lymphoblastic leukaemia & 279 & $34 \cdot 5(30.4$ to $38 \cdot 5)$ & 35 & $39 \cdot 3(26 \cdot 2$ to $52 \cdot 3)$ & $1.14(0.79$ to 1.65$)$ \\
\hline Acute non-lymphocytic leukaemia & 55 & $6.7(4.9$ to 8.5$)$ & 6 & $6.2(1.2$ to $11 \cdot 3)$ & $0.93(0.41$ to 2.11$)$ \\
\hline Lymphomas & 94 & $10.4(8.3$ to 12.6$)$ & 20 & $20.9(11.8$ to $30 \cdot 2)$ & $2.01(1.08$ to 3.76$) \dagger$ \\
\hline Hodgkin's disease & 45 & $4.8(3.4$ to 6.1$)$ & 10 & $10.3(3.9$ to 16.7$)$ & $2.16(0.87$ to 5.38$)$ \\
\hline Non-Hodgkin's lymphoma & 49 & $5 \cdot 7(4 \cdot 1$ to $7 \cdot 3)$ & 10 & $10 \cdot 7(4 \cdot 1$ to $17 \cdot 4)$ & $1.89(0.80$ to 4.47$)$ \\
\hline Central nervous system tumours & 263 & $31.3(27.5$ to $35 \cdot 1)$ & 23 & $24 \cdot 0(14 \cdot 2$ to $33 \cdot 8)$ & $0.77(0.52$ to 1.12$)$ \\
\hline Solid tumours & 377 & $46.7(41.9$ to 51.4$)$ & 57 & $65 \cdot 2(48 \cdot 2$ to $82 \cdot 1)$ & $1.40(1.02$ to 1.92$) t$ \\
\hline Sarcomas & 121 & $14.0(11.5$ to 16.5$)$ & 8 & $8.4(2.6$ to 14.3$)$ & $0.60(0.34$ to 1.08$)$ \\
\hline Rhabdomyosarcoma & 44 & $5 \cdot 5(3 \cdot 8$ to $7 \cdot 1)$ & 2 & $2.0(0.1$ to 4.9$)$ & $0.37(0.15$ to 0.95$) t$ \\
\hline Non-sarcomatous solid tumours & 256 & $32 \cdot 6(28 \cdot 6$ to $36 \cdot 7)$ & 49 & $56 \cdot 7(40 \cdot 8$ to $72 \cdot 6)$ & $1.74(1.19$ to 2.53$) t$ \\
\hline Neuroblastoma & 64 & $8 \cdot 5(6.4$ to $10 \cdot 6)$ & 8 & $9.4(2.9$ to 15.9$)$ & $1.10(0.51$ to 2.37$)$ \\
\hline Retinoblastoma & 33 & $4.4(2.9$ to 5.9$)$ & 8 & $9.4(2.9$ to 15.9$)$ & $2 \cdot 14(0.77$ to $5 \cdot 90)$ \\
\hline Wilms' tumour & 52 & $6.8(5.0$ to 8.7$)$ & 8 & $9.0(2.8$ to 15.3$)$ & $1.32(0.58$ to 3.03$)$ \\
\hline Malignant germ cell tumour & 27 & $3.2(2.0$ to 4.4$)$ & 9 & $10.5(3.6$ to 17.5$)$ & $3.29(1.06$ to 10.2$) \dagger$ \\
\hline Other malignant solid tumour & 80 & $9.7(7.6$ to 11.9$)$ & 16 & $18.4(9.4$ to 27.4$)$ & $1.89(0.96$ to 3.74$)$ \\
\hline All tumours & 1078 & 130.8 (123 to 139$)$ & 144 & $159 \cdot 1$ (133 to 185$)$ & $1.22(1.01$ to 1.47$) \dagger$ \\
\hline
\end{tabular}

$\mathrm{CI}=$ Confidence interval. ${ }^{\star}$ Bold if more than 10 cases; light type if less than 10 cases; $\uparrow \mathrm{p}<0.05$. 
Table 3 Age standardised incidence rates (ASRs) and standardised rate ratio (SRR) for childhood cancer in the WMHAR, $1989-92$ (four year period) (population figures derived from the 1991 census)

\begin{tabular}{|c|c|c|c|c|c|}
\hline \multirow[b]{2}{*}{ Tumour type } & \multicolumn{2}{|l|}{ White } & \multicolumn{2}{|l|}{ Asian } & \multirow[b]{2}{*}{$S R R(95 \% C I)$} \\
\hline & No of cases & $A S R^{\star}(95 \% C I)$ & No of case & $A S R^{\star}(95 \% C I)$ & \\
\hline Lymphoreticular tumours & 177 & $53.7(45 \cdot 8$ to $61 \cdot 6)$ & 32 & $87.9(57.0$ to 119$)$ & $1.64(1.03$ to 2.59$) t$ \\
\hline Leukaemias & 147 & $45.2(37.9$ to 52.5$)$ & 19 & $56.0(30.5$ to 81.4$)$ & $1.24(0.73$ to 2.09$)$ \\
\hline Acute lymphoblastic leukaemia & 120 & $37.1(30.4$ to 43.7$)$ & 16 & $47 \cdot 0(23 \cdot 7$ to $70 \cdot 3)$ & $1.27(0.71$ to 2.26$)$ \\
\hline Acute non-lymphocytic leukaemia & 23 & $7 \cdot 0(4 \cdot 1$ to $9 \cdot 8)$ & 2 & $5.7(0.1$ to 13.7$)$ & $0.82(0.21$ to 3.13$)$ \\
\hline Lymphomas & 30 & $8 \cdot 5(5.5$ to $11 \cdot 6)$ & 13 & $32 \cdot 0(14 \cdot 4$ to $49 \cdot 5)$ & $3.75(1.4$ to 10.3$) t$ \\
\hline Hodgkin's disease & 13 & $3.7(1.7$ to $5 \cdot 6)$ & 8 & $18.4(5.6$ to 31.2$)$ & $5.04(1.2$ to 20.8$) \dagger$ \\
\hline Non-Hodgkin's lymphoma & 17 & $4.9(2.6$ to 7.2$)$ & 5 & $13.6(1.5$ to 25.6$)$ & $2.78(0.65$ to 11.8$)$ \\
\hline Central nervous system tumours & 100 & $29.6(23.8$ to 35.4$)$ & 10 & $25 \cdot 8(9.6$ to $42 \cdot 1)$ & $0.87(0.47$ to 1.63$)$ \\
\hline Solid tumours & 157 & $47 \cdot 7(40 \cdot 2$ to $55 \cdot 2)$ & 24 & $73.0(43.5$ to 103$)$ & $1.53(0.92$ to 2.55$)$ \\
\hline Sarcomas & 46 & $13.6(9.6$ to $17 \cdot 5)$ & 4 & $10.3(0.1$ to 20.5$)$ & $0.76(0.30$ to 1.91$)$ \\
\hline Rhabdomyosarcoma & 15 & $4.6(2.2$ to 6.9$)$ & 2 & $4.8(0.1$ to 11.5$)$ & $1.05(0.23$ to 4.75$)$ \\
\hline Non-sarcomatous solid tumours & 111 & $34 \cdot 1(27 \cdot 8$ to $40 \cdot 5)$ & 20 & $62 \cdot 7(35 \cdot 1$ to $90 \cdot 3)$ & $1.84(1.0$ to 3.36$) \dagger$ \\
\hline Neuroblastoma & 28 & $8.9(5.6$ to $12 \cdot 2)$ & 2 & $6.6(0.1$ to $15 \cdot 6)$ & $0.74(0.21$ to 2.60$)$ \\
\hline Retinoblastoma & 13 & $4.1(1.9$ to 6.3$)$ & 4 & $13.1(0.3$ to 25.9$)$ & $3.20(0.59$ to 17.2$)$ \\
\hline Wilms' tumour & 23 & $7 \cdot 3(4 \cdot 3$ to $10 \cdot 2)$ & 3 & $9 \cdot 0(0.1$ to $19 \cdot 2)$ & $1.23(0.33$ to 4.61$)$ \\
\hline Malignant germ cell tumour & 9 & $2.7(0.9$ to 4.5$)$ & 5 & $15 \cdot 3(1.8$ to $28 \cdot 8)$ & $5.63(0.86$ to 36.8$)$ \\
\hline Other malignant solid tumour & 38 & $11 \cdot 2(7 \cdot 6$ to $14 \cdot 7)$ & 6 & $18.8(3.7$ to 33.9$)$ & $1.68(0.58$ to 4.86$)$ \\
\hline All tumours & 434 & $131.0(119$ to 143$)$ & 66 & $186 \cdot 7(141$ to 232$)$ & $1.43(1.05$ to 1.93$) \dagger$ \\
\hline
\end{tabular}

$\mathrm{CI}=$ Confidence interval. ${ }^{\star}$ Bold if more than 10 cases; light type if less than 10 cases; $\uparrow \mathrm{p}<0.05$.

germ cell tumours was apparent; there was also a non-significant doubling of the age standardised incidence rate for retinoblastoma. Central nervous system tumours and sarcomas appeared to be less common in Asians, though only rhabdomyosarcoma showed a significant deficit. The incidence of leukaemia was similar in white and Asian children.

Table 3 shows the second set of age standardised incidence rates, calculated for the four year period 1989-92 and based on the 1991 census. The values for white children were similar to those obtained from the 10 year period. There was a significant excess of all malignancies in Asians (standardised rate ratio 1.44). The age standardised incidence rates for lymphoreticular tumours and non-sarcomatous solid tumours were significantly higher than in white children. Among lymphoreticular tumours, the lymphomas showed a significant excess, particularly Hodgkin's disease. There was a non-significant threefold excess of retinoblastoma. Malignant germ cell tumours were nearly six times as common as in white children, though the standardised rate ratio did not reach significance. Central nervous system tumours and sarcomas seemed to be less common in Asians, though the significant deficit of rhabdomyosarcoma seen in the 10 year series was no longer apparent. To summarise, the same pattern was seen in both the 10 year and the four year series, namely that the incidence of all malignancies was significantly greater in Asian children than in white children, particularly for lymphomas and solid tumours (excluding sarcoma).

The age distribution of the children with Hodgkin's disease diagnosed between 1982 and 1992 was examined and Asian patients were found to be younger than white children. Thirteen Asian patients had a median age of 10 years 5 months, compared with 12 years 6 months for 49 white patients $(p<0.05)$. As this difference could be a product of differences in the age structure of the populations, the age specific incidence rates were also examined. Comparing the age specific incidence (10 year rates) in children less than 10 years with that at age 10-14 years, the relative risk in the younger group was higher for Asians (0.30) than for white children $(0 \cdot 16)$, though this difference was not statistically significant (risk ratio 1.94 , $95 \%$ confidence intervals 0.5 to $6 \cdot 6$ ).

For retinoblastoma, during the study period, bilateral cases accounted for $42 \%$ (16/38) of white children and $45 \%(5 / 11)$ of Asians, suggesting that the excess of retinoblastomas in Asians is not solely due to bilateral cases. Germ cell tumours were sited in the gonads in $90 \%$ (9/10) of Asian and 69\% (20/29) of white patients. When the 10 year rates were calculated separately for gonadal and extragonadal tumours, the excess in Asians was confined to the gonadal sites (age standardised incidence rate $9 \cdot 4$ for Asians, $2 \cdot 1$ for whites; standardised rate ratio $4 \cdot 4(1 \cdot 15$ to $16 \cdot 9))$.

To assess the accuracy of the population figures, the census counts were compared with data for schoolchildren in Birmingham, where $50 \%$ of the Asian children of the WMHAR live. Since 1990, local education authorities have collected data (by parental questionnaire) on the ethnic origin of children entering primary and secondary schools. Table 4 gives the figures collected in 1991 for primary schools in the City of Birmingham. They are compared with the number of children aged 5-6 years derived from the quinquennial (5-9) age band figures for each ethnic group and the proportion of Birmingham children aged 5 and 6 years. Comparison of the two figures suggests that the census may have underestimated Birmingham Asian children by $10 \%$.

The effect on the incidence rate of underenumeration was investigated by inflating the population counts for the ethnic minorities until the age standardised incidence rate reached the same value as that for white children. For the 10 year figures, a deficit of $18 \%$ in the Asian population figures would account for the excess, whereas for the four year figures the census would have to have missed $30 \%$ of Asian children.

\section{Discussion}

The pattern of cancer incidence in Asians revealed by this study is in agreement with the results of the previous investigations based on relative frequencies. ${ }^{78}$ Such confirmation 
might be expected, however, when it is considered that some of the white and Asian cases in the present series have also featured in these earlier studies. Seventy one per cent (35/49) of the Asians and $64 \%(324 / 505)$ of the white cases from the earlier West Midlands study ${ }^{8}$ also appear in the 10 year age standardised incidence rates. For the UKCCSG survey, ${ }^{7}$ however, only $20 \%$ of the Asians and $9 \%$ of white children originate from the WMHAR, so it is valid to compare the two sets of results.

The UKCCSG study suggested that there may be an increased risk of Hodgkin's disease, germ cell tumours, and retinoblastoma and a reduced risk of rhabdomyosarcoma and Wilms' tumour in Asian children living in the UK. It also concluded that the pattern and risk of leukaemia in Asians and white children was similar. With the exception of Wilms' tumour (where our rates are similar in the two groups) our age standardised incidence rates show the same general pattern, which confirms that the West Midlands cases adequately reflect the pattern of disease seen in Asians throughout the UK.

Agreement between the 10 year and four year rates might also be expected because of the overlap in the time periods. Forty nine Asians appear in the two sets of rates $(34 \%$ of cases in the 10 year rates and $74 \%$ in the four year rates). The choice of time periods was constrained by the need to centre on the years for which population figures were available (1987 and 1991) to calculate the person years at risk. Furthermore, two sets of age standardised incidence rates were derived because of doubts about the accuracy of the population denominators, rather than the number of cases.

In comparison with international rates for childhood cancer, our age standardised incidence rates for UK white children are similar to those reported by other UK and European registries, ${ }^{1}$ which range from 97 to 140 . In India, the Bombay and Bangalore cancer registries reported age standardised incidence rates of 70.9 (for the period 1970-9) and 58.6 (1982-4) respectively. These rates were among the lowest reported internationally. The completeness of registration in Indian registries was likely to have been poor compared with European registries, however. The excess of male cases in the Asian registries suggests that registration is particularly poor for girls.

Interpretation of our rates is particularly difficult in the absence of incidence rates from Pakistan and Bangladesh. Fifty two per cent of Asian children in the West Midlands are Muslims of Pakistani or Bangladeshi origin. One study ${ }^{11}$ found that $69 \%$ of Birmingham Pakistani mothers and $30 \%$ of the Muslims of other races were related to their husbands (the figures for Europeans, Afro-Caribbeans, and Indians are less than $1 \%$ ). The same study showed that congenital defects were more common in the children of consanguineous Muslims, but whether these children are also more likely to suffer from cancer is conjectural. The observed excess among Asians of retinoblastoma and germ cell tumours, where genetic factors have been implicated in the aetiology, ${ }^{12} 13$ might, at first sight, suggest a genetic susceptibility in Asians to which consanguinity might contribute. Our figures and the UKCCSG study show that the increase is not confined to bilateral retinoblastoma, however. If a genetic susceptibility to cancer existed in Asians, it might be through other mechanisms such as defects in DNA repair mechanisms.

The excess of lymphomas, particularly Hodgkin's disease in Asians, may be more readily explained in terms of environmental factors. Our data suggest that Asian patients are younger than white patients, a feature which is confirmed in other studies, ${ }^{74}$ and which has been linked to environmental factors associated with poor social conditions. Further evidence of the importance of socioeconomic factors comes from a 30 year survey of Hodgkin's disease in children aged under 15 years (all ethnic groups combined) in the West Midlands. ${ }^{15}$ This showed a significant increase in the mean age and in age specific incidence over time.

Against the figures from India, the rates we have calculated for UK Asians (159 and 187 from the 10 and four year surveys respectively) represent a huge excess of malignancies. The highest international cancer incidence rates previously reported ${ }^{1}$ were for Nigeria $(155 \cdot 6)$, USA Los Angeles white subjects (146.7), and Brazil, São Paolo (145.4); all these values are lower than those calculated for Asians in the West Midlands. It is highly unusual for a migrant group to express cancer rates higher than those of both the country of origin and the country of settlement. We should therefore consider other factors which may have led to such high rates. These are of two types: errors in the denominator (underestimating the population at risk) and errors in the numerator (number of cases).

Considering first the accuracy of the Labour Force Survey figures, the fallibility of survey based population figures is accepted. ${ }^{6}$ Although the $95 \%$ confidence intervals compensate for random sampling error and the clustering that occurs when households rather than people are sampled, the effects of bias (in the selection of the sample and in those who respond) cannot be quantified. It is thought that the Labour Force Survey is biased towards underestimating the Asian population in urban areas (J Haskey, personal communication). If cancer incidence rates in white and Asian children were the same, the Asian population would need to be underestimated by $18 \%$. Shortfalls of this size fall within the calculated $95 \%$ confidence intervals for the estimates. Although the 10 year rates shown here represent the best estimate of the true incidence rate in Asians, they do not provide conclusive evidence of an excess of childhood cancers.

Another criticism of the 10 year rates is that a single population figure for one year may not adequately represent the population at risk over a 10 year period. This method carries the assumption that the rate of population growth is constant over the study period. In ethnic 
Table 4 Childhood population of the City of Birmingham

\begin{tabular}{lcccccc}
\hline Source & White & Asian & Black & Other & $\begin{array}{l}\text { All } \\
\text { minorities }\end{array}$ & $\begin{array}{l}\text { All ethnic } \\
\text { groups }\end{array}$ \\
\hline $\begin{array}{l}\text { Census estimates } \\
\quad 5 \text { and 6 year olds }\end{array}$ & 18710 & 7310 & 2520 & 1280 & 11110 & 29810 \\
$\begin{array}{l}\text { BCC education department } \\
\quad \begin{array}{l}\text { and 6 year olds } \\
\text { Ratio OPCS/BCC figures }\end{array}\end{array}$ & $\begin{array}{c}17930 \\
1.04\end{array}$ & $\begin{array}{c}8100 \\
0.90\end{array}$ & $\begin{array}{c}2490 \\
1.01\end{array}$ & $\begin{array}{c}820 \\
1.56\end{array}$ & $\begin{array}{r}11410 \\
0.97\end{array}$ & $\begin{array}{c}29350 \\
1.01\end{array}$ \\
\hline
\end{tabular}

BCC $=$ Birmingham City Council.

minority populations, where birth rates may fluctuate and migration rates are high, ${ }^{16}$ this assumption may be invalid. For these reasons, the four year age standardised incidence rates, covering a shorter period and using census counts rather than estimates, are probably more reliable, despite being based on fewer cases.

Errors in the census population figures may have arisen due to misclassification. The census lists four categories of Asians, 'Indian', 'Pakistani', 'Bangladeshi' and 'other Asian', but only the first three are used in this study. In the West Midlands, 3300 children are described as 'other Asian'. A detailed breakdown of this category is not yet available; it is known to include East African Asians, but may also include non-Chinese orientals (for example, Vietnamese). Inclusion of this ethnically diverse 'other Asians' group, however, made little difference to the four year incidence rates. The rate for all malignancies decreased from $186 \cdot 7$ to $180 \cdot 3$ (136-224), but was still significantly higher than the rate for white children.

Doubt has been expressed whether the ethnic minorities were accurately enumerated in the 1991 census. ${ }^{17-20}$ The total population undercount for England and Wales in the 1991 census is believed to comprise around one million people, or $2 \%$ of the population, though $16-20 \%$ of this undercount is thought to belong to the ethnic minority population. ${ }^{21}$ Imbalances of the sex ratio suggest that young black adult males are particularly affected. Young men would be more mobile and thus elusive to the enumerators than home based women and children. ${ }^{17}$ In a survey of the Parkside health district of London, ${ }^{18}$ however, $12 \%$ of Asians and $8 \%$ of all respondents reported that their census form had not been collected, a factor which might significantly affect the childhood population count.

Figures from Birmingham education department (table 4) suggest that $10 \%$ of Asian children may have been missed by the census (assumptions made in the calculation of this figure mean that it should be regarded as only approximate). There is good agreement in the numbers for all ethnic minorities, implying that misclassification of Asian children into the 'other' category may contribute to the deficit. If, however, population underestimation were the sole reason for the high rates, a deficit of $30 \%$ of Asian children would be required. An undercount of this size, two to three times as large as other estimates, is unlikely.

Consideration should then be given to the effects of numerator error on the age standardised incidence rates. The number of cases might be inflated if sick children brought to this country for treatment, or visitors who fell ill during their stay, were passed off as UK residents. The scale of this practice would have to be very large to account for the excess of malignancies, however. For example, assuming a census undercount of $10 \%$ of Asian children, $14(21 \%)$ of the 66 cases diagnosed between 1989 and 1992 would have to have been non-residents. This number may be compared with the experience of the Birmingham Children's Hospital in the 11 year period of this study, during which six Asian children diagnosed abroad and one visiting child who developed cancer were seen (these cases were not included in the calculation of the incidence rates). It would seem unlikely, then, that patients from abroad contribute greatly to the excess of malignancies.

Although incidence rates in the ethnic minorities may aid our understanding of the aetiology of childhood cancer, their value must be questioned where population figures are not reliable. ${ }^{17-19}$ Underenumeration of ethnic minorities in the 1991 census may have contributed to the high rates seen in Asians, but the deficit that would be required to produce these figures far exceeds other estimates of the likely undercount. The Asians show a different pattern of cancers, with an excess of lymphomas, deficit of rhabdomyosarcomas, and an excess of some solid tumours which matches that reported in another study. ${ }^{7}$ Although the reliability of the incidence rates presented here is in doubt, they do provide cause for concern that Asian children living in the West Midlands may be at a greater risk of developing childhood cancer than white children. Confirmation of this finding from other regions of the UK, and quantification of the ethnic population undercount from the 1991 census are required before undertaking research into the geographical, biological, and social conditions of Asian children to identify factors which may have led to an increased risk.

The West Midlands Regional Children's Tumour Research Group has received financial support from the West Midlands Regional Health Authority and the Special Trustees of the Former United Birmingham Hospitals.

1 Parkin DM, Stiller CA, Draper GJ, Bieber CA, Terracini B, Young JL, eds. International incidence of childhood cancer.
LARC scientific publications No 87. Lyon: IARC, 1988 .

2 Kramer S, Meadows AT, Jarrett P. Incidence of childhood cancer: experience of a decade in a population based cancer: experience of a decade in a pop
registry. F Natl Cancer Inst 1983; 70: 49-55.

3 Young JL, Gloeckler Ries L, Silverberg E, Horm JA, Miller RW. Cancer incidence, survival and mortality for children younger than age 15 years. Cancer 1986; 58: 598-602. 4 Goodman MT, Yoshizawa - CN, Kolonel LN. Incidence trends and ethnic patterns for childhood leukaemia in Hawaii: 1960-1984. Br f Cancer 1989; 60: 93-7.

5 Goodman MT, Yoshizawa CN, Kolonel LN. Ethnic patterns of childhood cancer in Hawaii between 1960 and 1984. Cancer 1989; 64: 1758-63. 
6 Haskey J. The ethnic minority populations resident in private households - estimates by county and metropolitan districts of England and Wales. Population Trends 1991; 63: 22-35.

7 Stiller CA, McKinney PA, Bunch KJ, Bailey CC, Lewis IJ. Childhood cancer and ethnic group in Britain: a United Kingdom Children's Cancer Study Group (UKCCSG) Kingdom Children's Cancer Study

study. Br f Cancer 1991; 64: 543-8.
8 Muir KR, Parkes SE, Mann JR, Stevens MCG, Cameron AH. Childhood cancer in the West Midlands: incidence and survival 1980-1984, in a multi-ethnic population. Clin Oncol 1992; 4: 177-82.

9 Birch JM, Marsden HB. A classification scheme for childhood cancer. Int $\mathcal{F}$ Cancer 1987; 40: 620-4

10 Boyle P, Parkin DM. Statistical methods for registries. In: Jensen OM, Parkin DM, McLennan R, Muir CS, Skeet RG, eds. Cancer registration: principles and methods. LARC scientific publications No 95. Lyon: IARC, 1991: 126-58.

11 Bundey S, Alam H, Kaur A, Mir S, Lancashire R. Why do UK-born Pakistani babies have high perinatal and neonK-born Pakistani babies have high perinatal and neonatal mortality rates? Pediatr Perinat Epidemiol 1991; 5:

12 Vogel F. Genetics of retinoblastoma. Hum Genet 1979; 52: $1-54$.
13 Johnston HE, Mann JR, Williams J, et al. IRESCC: casecontrol study in children with germ-cell tumours. Carcinogenesis 1986; 7: 717-22.

14 Stiller CA, Parkin DM. International variations in the incidence of childhood lymphomas. Paediatr Perinat Epidemiol 1990; 4: 302-24.

15 Parkes SE, Coad NAG, Muir KR, Jones TJ, Cameron AH, Mann JR. Hodgkin's disease in children in the West Midlands 1957-86: a large population-based study. Pediatr Hematol Oncol 1994; 11: 471-86.

16 Haskey J. The ethnic minority populations of Great Britain: estimates by ethnic group and country of birth. Population Trends 1991; 60: 35-8.

17 Carr-Hill RA. Underenumeration in the 1991 census: census inaccurate for many ethnic groups. $B M F$ 1993; 307: 1563-4

18 Victor C. Underenumeration in the 1991 census: forms not retrieved. BMF 1993; 307: 1564.

19 Glover GR. Sex ratio errors in census data. BMF 1993; 307:

506.
20 Thompson EJ. Underenumeration in the 1991 census. BMF 1993 307: 803 .

21 Teage A, Haskey J. Counting ethnic populations. Royal Statistical Society News 1994;21(5): 6. 